10.12957/demetra.2013.6562

\title{
O puerpério e sua dimensão sociocultural na perspectiva de mulheres moradoras da região de Manguinhos - Rio de Janeiro, RJ
}

\author{
Puerperium and its sociocultural dimension from the perspective of women living in \\ Manguinhos - Rio de Janeiro, RJ, Brazil
}

\author{
Mirian Ribeiro Baião ${ }^{1}$ \\ Marta Maria Antonieta de Souza Santos' \\ Beatriz Della Líbera² \\ Raphaela Corrêa Monteiro Machado² \\ ' Departamento de Nutrição Social e Aplicada, \\ Instituto de Nutriçã̃o Josué de Castro, Centro de \\ Ciências da Saúde. Universidade Federal do Rio \\ de Janeiro. Rio de Janeiro, RJ, Brasil. \\ 2 Programa de Pós-graduação em Nutrição, \\ Instituto de Nutrição Josué de Castro, Centro de \\ Ciências da Saúde. Universidade Federal do Rio \\ de Janeiro. Rio de Janeiro, RJ, Brasil. \\ Correspondência / Correspondence \\ Mirian Ribeiro Baião \\ Departamento de Nutrição Social e Aplicada, \\ Instituto de Nutrição Josué de Castro, Centro de \\ Ciências da Saúde. Universidade Federal do Rio \\ de Janeiro \\ Av. Carlos Chagas Filho, 373 - Edifício dos \\ Institutos Bloco J, $2^{0}$ piso - Ilha do Fundão \\ 21941-590 Rio de Janeiro - RJ, Brasil \\ E-mail:mirianbaiao@uol.com.br
}

\section{Resumo}

Introdução: o puerpério, popularmente identificado por resguardo, é definido como o período posterior ao parto, que dura cerca de quarenta dias e se constitui em uma fase de intensas mudanças biopsicossociais na vida da mulher. O exercício do cuidado integral e da atenção à saúde das puérperas implica no entendimento de suas crenças para a vivência desse momento. Objetivo: retratar sentidos e significados de crenças, prescrições e interdições durante o puerpério por mulheres urbanas socialmente vulneráveis. Métodos: estudo qualitativo, fundamentado na perspectiva interpretativista. Dados construídos por entrevistas semiestruturadas, gravadas e transcritas literalmente. Análise realizada com base em estudo de conteúdo, modalidade temática, adaptada. Resultados e Discussão: grupo de estudo constituído por mulheres jovens e adolescentes, a maioria com ensino fundamental incompleto, dedicada ao lar e vivendo com o companheiro. O resguardo representa um período de ameaça à saúde e à vida da mulher, a qual deve permanecer afastada de esforço físico e atividade sexual. Implica na necessidade de apoio físico e emocional por parte da família ou pessoas próximas. A mulher é encorajada a optar por comida leve: frango, arroz, verduras e frutas, evitando comida pesada, carregada ou reimosa. Para produzir leite bom e suficiente: leite, mate, cerveja e líquidos. Conclusão: o resguardo é um processo biológico, histórico, social, emocional e cultural. Faz-se necessário compreender os diferentes aspectos que delimitam práticas e atitudes, com vistas ao alcance do equilíbrio entre preceitos socioculturais e científicos, proporcionando às mulheres a vivência do resguardo com serenidade e confiança.

Palavras-chave: Período pós-parto. Quarentena. Alimentos para gestantes e nutrizes. Conhecimentos, Atitudes e Práticas em Saúde. 


\section{Abstract}

Introduction: puerperium, also known as postpartum confinement, is defined as a period of forty days after childbirth and is a phase of intense biological, psychological and social changes in women's life. The practice of whole healthcare of puerperas involves understanding their beliefs to live this moment. Objective: to represent the senses and meanings of beliefs, prescriptions and interdictions during puerperium of women living in vulnerable social urban conditions. Methods: it was a qualitative study, based on an interpretative perspective. Data was constructed using semi-structured interviews, which were recorded and literally transcribed and explored using content analysis in accordance with the thematic and adapted mode,... Results and Discussion: the group under study constituted of young women and adolescents; the majority did not complete high school, were housewives and lived with a partner. The postpartum confinement represents a period of threat to women's health and life, in which women must be away from physical effort and sexual activity, and requires physical and emotional support from the family and people who are close to them. Women are encouraged to choose light food as chicken, rice, green vegetables and fruits, and avoid "heavy" and fatty foods. To produce good and sufficient milk, they must drink milk, mate, beer and liquids. Conclusion: postpartum confinement is a biological, historical, social, emotional and cultural process. It is necessary to comprehend the different aspects that delimit practices and attitudes to reach the equilibrium between social and cultural precepts and scientific precepts and to promote a postpartum confinement living with serenity and confidence.

Key words: Postpartum Period. Quarantine. Foods for Pregnants and Breast-feeding Mothers. Health Knowledge, Attitudes, Practice.

\section{Introdução}

O puerpério, popularmente identificado por resguardo, quarentena ou dieta, é definido como o período posterior ao parto e se constitui em uma fase de intensas mudanças biopsicossociais na vida da mulher. Trata-se de um período no qual transbordam fortes emoções, mudanças e restaurações, interações, encontros e trocas que o caracterizam como um acontecimento sociocultural permeado por crenças, costumes e interdições, cujos significados são capazes de transcender os eventos fisiológicos que o marcam. ${ }^{1}$ 
Estudos socioantropológicos ${ }^{2,3}$ revelam que as crenças e os significados culturais presentes em todo o ciclo gravídico puerperal modulam práticas de resguardo, isto é, modulam um conjunto de restrições alimentares e de atividades da mulher durante os quarenta dias pós-parto.

Tais práticas se originam e se respaldam em relatos de experiências bem ou mal sucedidas no pós-parto das mulheres, que uma vez transmitidas sucessivamente, por meio das gerações, ganham confiança e despertam dogmatismo, ou seja, integram o legado cultural daquele grupo social e passam a ser percebidas como verdade absoluta e indiscutível. Nesse sentido, as mulheres significam o resguardo como período de convalescença, de respeito às normas e regras culturalmente aprendidas que visam protegê-las de uma recaída. ${ }^{4-6}$

É importante lembrar que em 1993, por esforço dos movimentos sociais feministas, o termo integralidade da saúde foi pioneiramente utilizado pelo Programa de Assistência Integral à Saúde da Mulher (PAISM). Buscava-se por meio do rompimento com o paradigma materno-infantil no qual a mulher é reconhecida apenas no seu papel de mãe, nutriz e cuidadora, sendo a maior preocupação o cuidado com o recém-nascido - o alcance da dimensão vertical da integralidade, ou seja, que a mulher fosse vista como sujeito da atenção. ${ }^{7}$ Contudo, passadas perto de duas décadas, dados do Ministério da Saúde ${ }^{8}$ apontavam que a avaliação do bebê e o controle da fecundidade e do processo reprodutivo eram o centro das atenções dos profissionais de saúde, e, consequentemente, também das mulheres na consulta de puerpério. Nesse contexto de desatenção à mulher puérpera no espaço institucional da saúde, o cuidado pós-parto efetivamente ocorre no meio familiar. ${ }^{9}$

Observa-se, portanto, que apesar do reconhecimento do Ministério da Saúde de que condutas baseadas apenas nos aspectos biológicos se mostram insuficientes para o atendimento a todas as necessidades da mulher na gravidez, parto e puerpério, ${ }^{10}$ as dimensões subjetivas, quer sejam a história de vida, as angústias e os sentimentos dessa mulher, ainda são negligenciadas pelos profissionais de saúde. Assim, a compreensão dos valores e significados atribuídos pela mulher durante a vivência do puerpério é um passo extremamente importante para o exercício do cuidado integral na atenção à saúde da mulher no pós-parto.

Este trabalho tem por objetivo retratar uma reinterpretação dos sentidos e significados de crenças, prescrições e interdições culturais, especialmente alimentares, atribuídas ao puerpério por mulheres urbanas pertencentes a grupo-socialmente vulnerável. Espera-se contribuir para a integração desses elementos socioculturais ao cuidado da mulher durante o ciclo gravídico puerperal, estabelecendo-se, dessa forma, uma prática em saúde efetiva, integral e humanizada. 


\section{Métodos}

Conduzido pela abordagem qualitativa e fundamentado na perspectiva interpretativista, que compreende a ação humana como significativa, o presente estudo procura ser fiel à experiência vivida e valoriza a subjetividade. ${ }^{11}$

O número de sujeitos que fizeram parte da pesquisa foi definido pelo critério de reincidência e saturação de sentidos, ${ }^{12,13}$ tendo sido incluídas 18 gestantes e oito puérperas. Todas as mulheres viviam na região de Manguinhos, no Rio de Janeiro, e foram identificadas em uma Unidade Básica de Saúde (UBS) local.

Os dados foram construídos por meio de entrevistas orientadas por roteiro semiestruturado, em salas reservadas da UBS e gravadas em áudio. Ao final de cada entrevista, o pesquisador procedia à transcrição literal e acrescentava suas observações ao texto.

A análise do material empírico foi realizada com base em uma adaptação da análise de conteúdo em sua vertente temática, ${ }^{14}$ tendo sido desenvolvidas as etapas de leitura exaustiva, quando foram levantados os questionamentos iniciais, organização e codificação de dados com vistas à identificação de temas, categorias êmicas e "núcleos de sentido" e análise propriamente dita. ${ }^{14}$

Uma vez destacados os temas, as categorias e os "núcleos de sentidos", a análise buscou os sistemas de significados, crenças, valores e ações relacionados ao puerpério. Iniciou-se, assim, um processo de reconstrução e compreensão das autointerpretações dos sujeitos do estudo, contextualizadas pelas experiências vividas. Simultaneamente, procedeu-se o diálogo e o confronto dessas reconstruções e compreensões com a literatura.

O estudo foi aprovado pelo Comitê de Ética em Pesquisa da Escola Nacional de Saúde Pública Sérgio Arouca (parecer n¹22/04), e as participantes assinaram o Termo de Consentimento Livre e Esclarecido.

\section{Resultados e discussão}

\section{O cenário e os sujeitos da pesquisa}

As 18 gestantes e oito puérperas que participaram do estudo tinham entre 15 e 46 anos. As gestantes apresentaram média de idade de 21,2 anos e as puérperas de 29,9 anos, podendo-se dizer que o grupo foi constituído por mulheres jovens. Fizeram parte sete adolescentes, sendo seis gestantes e uma puérpera. A inclusão das adolescentes buscou maior alcance da abrangência de sentidos e significados. 
Com relação à educação e ocupação, 14 não completaram o ensino fundamental, sete tinham alguma atividade remunerada, 15 se dedicavam ao lar, três adolescentes revelaram não ter nenhuma atividade e uma era estudante.

A maior parte (18) declarou que vivia com o marido ou o companheiro, 14 permaneciam unidas ao primeiro cônjuge e dez eram primíparas. Do conjunto, seis eram nordestinas e viviam no Rio de Janeiro na época da entrevista.

\section{O período do resguardo}

Para as mulheres entrevistadas, o resguardo é o período logo após o parto, que dura cerca de quarenta-dias, no qual é necessário ter o máximo de repouso.

Na crença popular, o resguardo representa tempo de grande ameaça à saúde e à vida da mulher. Durante os quarenta dias que se sucedem ao parto, a mulher encontra-se em um estado entre a saúde e a doença, pois seu corpo, que se abriu no momento do parto, permanecerá exposto a doenças até que se feche no quadragésimo dia. ${ }^{6,9,15,16}$ Essa situação de instabilidade é considerada perigosa pelo fato de a mulher estar "com o pé na sepultura,"2 por isso, para se proteger dos perigos, há a necessidade de obedecer às regras e manter-se afastada de diversas atividades domésticas, que nesse período são proibidas.

Durante o resguardo, de acordo com as gestantes e puérperas, a mulher também não pode ter relação sexual. A regra é esperar o resguardo terminar.

No estudo de Salim et al., ${ }^{17}$ que abordou a sexualidade e as mudanças corporais no período puerperal, para o início da atividade sexual, na concepção das mulheres entrevistadas, é preciso respeitar "o tempo do próprio corpo", pois em geral, é comum estar presente o medo associado à cicatrização do útero e da região perineal, à dor durante a relação e à possibilidade de uma nova gravidez. ${ }^{4,17}$

As mulheres do presente estudo interpretavam que se esses dois componentes, esforço e atividade sexual, fossem realizados, a mulher poderia "quebrar" o resguardo e vir a sentir fortes dores na barriga e na cabeça, podendo "até ficar maluca".

A quebra do resguardo tem o significado de aquisição de problemas de saúde no futuro, pois a realização de uma das restrições do resguardo é suficiente para ameaçar o bem-estar físico e emocional da mulher, podendo gerar adoecimento. ${ }^{9}$ Por isso, as mulheres evitavam fazer qualquer tipo de atividade que exigisse um maior esforço e, as que podiam, dedicavam-se mais ao bebê. Nesse sentido, todas as puérperas conseguiram alguém, quase sempre outra mulher, para ajudar com as atividades mais pesadas, como lavar roupa. As gestantes também estavam preocupadas 
com esse aspecto e já tentavam combinações, principalmente com familiares, para providenciar o apoio que iriam necessitar.

No período de resguardo, a ajuda à mulher se estabelece por meio de uma complexa rede de relações em que outras mulheres, da família ou amigas próximas, têm participação preponderante no apoio físico e emocional e no aconselhamento com relação ao cuidado da mulher e do recémnascido. ${ }^{9,18}$

Embora a alimentação não tenha sido apontada como um fator que "quebra" o resguardo, durante esse período-a mulher ficava sujeita a uma forte interferência das restrições alimentares. De modo geral, as mulheres acreditavam que-enquanto a cicatrização não ocorresse, elas não poderiam comer "comida pesada, carregada ou reimosa".

Uma vez o período do resguardo tendo a conotação de "perigo" para a saúde da mulher e do bebê, há de se cuidar para que a alimentação ingerida seja compatível com essa situação de fragilidade: leve, sem temperos fortes, com pouca gordura.

Estudos junto a populações pesqueiras e ribeirinhas ${ }^{2,19-21}$ identificaram que a condição de reimoso é dada ao alimento que, ingerido em situações de vulnerabilidade orgânica (e simbólica), apresenta potencial perigo ao fluxo de líquidos corporais (humores) pela baixa capacidade do organismo para resistir aos seus efeitos (força), provocando doenças (recaída).

No presente estudo, os alimentos classificados como pesados, carregados ou reimosos foram salsichas, carne de porco e derivados, carnes gordas, carnes salgadas, gordura, pato, feijão (à noite), café, chocolate, refrigerante, aipim, batata doce, sardinha, peixes, frutos do mar, abóbora de leite, melancia e ovos. "Assim... Uma linguiça, não pode comer, né? Um bacon não pode comer. Uma carne-seca, não pode comer. Muita coisa a gente não pode comer [...] A gente não pode comer coisa reimosa" (P2).

Na concepção das puérperas, de acordo com a lógica da "quebra do resguardo", se ingerissem preparações/alimentos interditos, o local, especialmente "se foram dados pontos", poderia ficar com mau cheiro e até inflamar, o que afetaria a cicatrização.

Uma gestante contou que sua cunhada, por não acreditar nessas proibições, "comeu favada (fava com mocotó) quando teve neném e sofreu bastante porque teve os pontos inflamados com pus durante um bom tempo".

Tanto as gestantes quanto as puérperas disseram que essas regras e tradições faziam parte da linguagem do povo, ou seja, era o povo quem dizia isso, principalmente os mais velhos, passando de mãe para filha.

Somente uma puérpera referiu que comeu ovos porque a médica disse que não tinha problema, mesmo assim, tal fato ocorreu alguns dias após o parto. As demais não ousaram comer os alimentos 
proibidos durante o resguardo, e todas as gestantes relataram que não comeriam de jeito nenhum os alimentos/preparações proibidos.

Nos estudos de Maués, ${ }^{2}$ Silva ${ }^{19}$ e Nakano et al. ${ }^{6}$ foi observado que as práticas alimentares no pós-parto são respaldadas nas crenças populares que alegam a existência de riscos específicos à saúde das mulheres associados à ingestão de determinados tipos de alimentos, como: carne suína, ovos e algumas espécies de peixe com riscos de infecção do útero, febre e corrimento; frutas ácidas com riscos de inflamação. Nessas populações estudadas a crença é de que se a mulher ingerir um desses alimentos durante o resguardo poderá morrer ou ficar "estragada", isto é, se tornar estéril.

Há certa tendência a crer nas proibições, mesmo que os profissionais de saúde se manifestem contrários a essas regras. Embora a gestante procure compartilhar suas dúvidas com o profissional que a assiste, as experiências apreendidas e/ou vivenciadas também são consideradas relevantes para as mulheres. ${ }^{22}$

No presente estudo, para a maioria das mulheres, se o médico não falasse nada, era melhor seguir o que o povo mandava e não comer os alimentos citados como reimosos ou carregados em hipótese alguma. E, se o médico dissesse que não tinha problema a mulher comer esses alimentos após o parto, ainda assim, era melhor seguir as recomendações populares, evitando qualquer risco.

As crenças advindas das relações familiares e sociais e de toda a história anterior e atual que rodeia as puérperas constroem valores socioculturais que elas carregam consigo pela vida. No processo de formação de suas identidades, o contexto em que vivem e os ensinamentos passados pelos mais velhos têm importância crucial. Por isso, abandonar as regras socioculturais apreendidas em suas histórias de vida em favor de preceitos científicos orientados pelo médico traz insegurança para as puérperas. ${ }^{23}$

Algumas atitudes incorporadas pelas mulheres e impulsionadas por parentes, amigos e pessoas próximas são mais valorizadas do que o conhecimento científico, pois propiciam o aumento da autoconfiança das mulheres por permitir que estas anunciem à sociedade a reprodução de saberes e funções de uma boa mãe, responsável e protetora de um ser vulnerável. ${ }^{24,25}$

Assim como existiam as proibições, para as entrevistadas, no resguardo, a mulher só deve comer duas categorias de alimentos/preparações:

a) "Comida leve", que incluía frango, arroz, feijão, verduras, frutas e fígado.

As puérperas referiram que não comiam qualquer tipo de carne que não fosse frango (cozido, ensopado, assado ou na canja) nos primeiros dias de resguardo.

As gestantes também indicaram o frango como o alimento que deveria ser mais consumido nesse período. 
Uma gestante nordestina relatou que, na sua terra, a mulher que está no início do resguardo toma um caldo especial feito com galinha caipira. Ela própria havia tomado na gravidez anterior, mas como era a sogra quem fazia e ela não havia aprendido, não sabia como iria fazer para tomar o referido caldo, o que a estava deixando apreensiva.

As mulheres referiram sentir muita fome durante o puerpério, mas a sede foi mais enfatizada, tornando a água essencial. "É muita fome que dá, muita sede também, a gente bebe muita água".

b) "Alimentos/preparações que ajudam na amamentação", tendo sido citados leite e preparações à base de leite - canjica, arroz-doce, vitamina (fruta batida com leite) etc. -, mate, cerveja preta e líquidos em geral.

Após o parto, a mulher inicia o processo de amamentação, o qual também é carregado de significações.

Uma das questões muito associadas à amamentação é a dieta materna. A mulher que amamenta precisa se alimentar adequadamente para produzir um leite bom e suficiente.

Embora circulasse entre as mulheres que esses alimentos podiam ajudar na amamentação, aumentando a produção do leite, nem sempre seriam consumidos por ocasião do resguardo, devido à privação econômica.

A puérpera Pl atribuiu a Deus o fato de ter muito leite e estar conseguido amamentar, porque a sua alimentação continuava insuficiente.

Tanto os profissionais de saúde quanto a família, a sociedade e a própria lactante cobram responsabilidades perante o aleitamento materno. Como este se trata de um ato determinado pela vivência da lactante em sociedade, uma experiência repassada de geração para geração e até mesmo uma tradição familiar, o valor sociocultural atribuído à amamentação faz com que a mulher se sinta pressionada a amamentar, não lhe sendo conferido o direito de errar. ${ }^{23,26,27}$

Houve uma puérpera que chegou a revelar que o leite materno é como o sangue da mãe: “[...] A gente tem que comer tudo na hora certa, direitinho, porque se não... A criança toma, mama e não se alimenta direito, né? $\mathrm{E}$ você emagrece, que ele chupa teu sangue, como se fosse o sangue da gente o leite da gente" (P2).

Para as entrevistadas, de modo geral, a grávida pode comer de tudo e isso não faz mal para o bebê, mas quando se está amamentando a situação muda.

As mulheres acreditavam que tudo que a mãe come passa para o bebê pelo leite e, ainda, alguns alimentos interferem no intestino da criança, podendo dar cólica. Elas tinham muito medo de 
diarreia, prisão de ventre e cólica na criança. Assim, a mulher que está amamentando tem motivos para cuidar mais da sua alimentação.

A mulher acredita que para produzir um leite considerado por ela como forte e em boa quantidade, ela necessita de algumas condições mínimas de saúde, dentre elas uma boa alimentação, que, por sua vez, abrange a não ingestão de alimentos que possam prejudicar a saúde do bebê e o consumo de alimentos que poderiam beneficiar a saúde da criança. Tendo em vista a noção que as mulheres têm sobre a transferência de nutrientes de seu organismo para compor o leite materno, a boa alimentação extrapola a necessidade de manter sua própria saúde ou bem-estar e visa atender melhor às necessidades do bebê. ${ }^{28}$

A preocupação com a saúde do bebê se tornava concreta no puerpério. Na gestação, a criança estava mais protegida no ventre materno. Após o nascimento, a mulher procurava ficar atenta às reações da criança porque podiam estar associadas à dieta materna, conforme os testemunhos abaixo: "Evitar comer besteira por causa do leite. Acredito que os alimentos podem passar pelo leite e prejudicar o bebê" (P1).

Não comi! Disseram que não pode, eu não comi. Vontade não faltou. Eu não comi. Porque eu fico morrendo de medo de dar cólica, dar alguma coisa, né, que passa pro leite, né? Aí eu não como. Não posso comer nada. Só isso mesmo, fruta, café eu não posso, refrigerante. Às vezes me dá uma raiva [...] Eu morro de vontade de comer coca-cola, essas coisa assim, não pode. Que ela não tem cólica, não tem nada, aí eu fico com medo dela ter (P4).

Mas aí vamos prevenir, né? Eu não vou comer coisa demais. Porque se eu... Por exemplo, comer muita banana, dá prisão de ventre nele, essas coisas. A gente tem que saber o que come. Não é tudo que a gente pode comer não, quando a gente tá dando de mamar, porque prejudica o bebê. Tem que chupar bastante laranja porque se não ele não vai evacuar, aí dá cólica nele (P2).

A puérpera P4 sinaliza que a prevenção de ocorrência de cólicas no seu bebê a motivou a excluir alimentos preferidos, exigindo sacrifício de sua parte, mas que se justificava, pelo fato de afastar o sofrimento do seu filho, no caso a cólica. O mesmo relato foi encontrado no estudo de Oliveira et al $^{29}$, que identificou a prevenção de cólicas como o principal motivo para a exclusão de alimentos específicos durante a lactação. Os folhosos aparecem frequentemente como geradores de cólicas no bebê, sendo retirados da dieta habitual da mulher, e para o tratamento das cólicas, cita-se o uso de chás, ambas as práticas presentes no senso comum. ${ }^{23,29}$

Assim, o puerpério é um período em que a mulher precisa ter alguns cuidados para garantir uma boa e rápida recuperação de seu organismo e prevenir intercorrências no estado de saúde do bebê, especialmente para aquelas que estavam amamentando. 


\section{Conclusão}

O período do resguardo deve ser considerado um processo não apenas biológico, mas também histórico, social, emocional e culturalmente constituído. As crenças influenciam de maneira significativa a vivência da mulher dessa fase.

É importante que os profissionais de saúde compreendam a construção sociocultural das prescrições e interdições no puerpério que circulam na sociedade de geração em geração, delimitando práticas e atitudes. A negação ou a repreensão de tais práticas pode gerar insegurança e conflito para as mulheres num período imensamente carregado de sentimentos e emoções.

Há que se considerar a lógica que fundamenta as crenças, buscando a reconstrução das mesmas, a fim de alcançar o equilíbrio entre os preceitos socioculturais e científicos, de forma a proporcionar à mulher a segurança de que necessita para experimentar o resguardo com tranquilidade, serenidade e confiança.

\section{Referências}

1. Carraro TE. A mulher no período puerperal: uma visão possível. Texto Contexto Enferm. 1997;1(1): 84-91.

2. Motta-Maués AM. Lugar de mulher: representações sobre os sexos e práticas médicas na Amazônia (Itapuã/Pará). In: Alves PC, Minayo MCS (orgs.). Saúde e doença: um olhar antropológico. Rio de Janeiro: FIOCRUZ; 1994. p. 33-45.

3. Campos MS. Poder, saúde e gosto: um estudo antropológico acerca dos cuidados possíveis com a alimentação e o corpo. São Paulo: Cortez; 1982.

4. Acosta DF, Gomes VLO, Kerber NPC, Costa CFS. Influências, crenças e práticas no autocuidado das puérperas. Rev esc enferm USP (online). 2012;46(6):1327-33.

5. Luz AMH, Berni NIO, Selli L. Mitos e tabus da maternidade: um enfoque sobre o processo saúdedoença. Rev Bras Enferm. 2007;60(1):42-8.

6. Nakano AMS, Beleza AC, Gomes FA, Mamede FV. O cuidado no "resguardo": as vivências de crenças e tabus por um grupo de puérperas. Rev Bras Enferm. 2003;56(3):242-47.

7. Souto KMB. A Política de Atenção Integral à Saúde da Mulher: uma análise de integralidade e gênero. SER Social. 2008;10(22):161-82.

8. Brasil. Ministério da Saúde. Secretaria de Atenção à Saúde. Departamento de Ações Programáticas Estratégicas. Política nacional de atenção integral à saúde da mulher: princípios e diretrizes. Brasília: Ministério da Saúde, 2007. Disponível em: http://portal.saude.gov.br/portal/arquivos/pdf/Polit_ Nac_At_In_Saude_Mulher_Princ_Diretr.pdf 
9. Stefanello J, Nakano AMS, Gomes FA. Crenças e tabus relacionados ao cuidado no pós-parto: o significado para um grupo de mulheres. Acta paul enferm (online). 2008;21(2):275-81.

10. Brasil. Ministério da Saúde. Pré Natal e puerpério: atenção qualificada e humanizada: manual técnico. Brasília, DF: Ministério da Saúde; 2006. (Direitos Sexuais e Direitos Reprodutivos, Caderno n.5).

11. Schwandt TA.Três posturas epistemológicas para a investigação qualitativa. In: Denzin NK, Lincoln YS (orgs.). O planejamento da pesquisa qualitativa: teorias e abordagens. Porto Alegre: Artmed; 2006. p. 193-217.

12. Minayo MCS. O desafio do conhecimento: pesquisa qualitativa em saúde. São Paulo: Hucitec; Rio de Janeiro: Abrasco; 2007.

13. Morse JM. Critical issues in qualitative research methods. Thousand Oaks, CA: Sage; 1994.

14. Bardin L. Análise de conteúdo. Lisboa: Edições 70; 2002.

15. Baião MR, Deslandes SF. Alimentação na gestação e puerpério. Rev Nutr (online). 2006;(2):245-53.

16. Panzutti NM. Impureza e perigo para povos de floresta. Ambient soc (online). 1999;5:69-77.

17. Salim NR, Araújo NM, Gualda DMR. Corpo e sexualidade: a experiência de um grupo de puérperas. Rev Latinoam Enferm. 2010;18(4):[08 telas].

18. Penna LH, Carinhanha JI, Rodrigues RF. A mulher no pós-parto domiciliar: uma investigação sobre essa vivência. Esc Anna Nery (online). 2006;10(3):448-55.

19. Silva MGSN. Dieta Alimentar de mulheres grávidas e paridas em áreas ribeirinhas da Amazônia. In: Simpósio Temático Gênero, Cultura e Desenvolvimento: Um Debate na Amazônia. UFSC Florianópolis; 2008. Disponível em: http://www.fazendogenero.ufsc.br/8/sts/ST49/Maria_das_ Gracas_Nascimento_Silva_49.pdf

20. Rodrigues AG. Buscando raízes. Horiz antropol (online). 2001;7(16):131-44.

21. Boehs AE, Althoff CR, Elsen I, Nascimento MG. Crenças, condutas e cuidados no período grávidopuerperal das mulheres de uma comunidade pesqueira. Rev Ciên Saúde. 1993;12(1):54-66.

22. Líbera BD, Saunders C, Santos MMAS, Rimes KA, Brito FRSS, Baião MR. Avaliação da assistência pré-natal na perspectiva de puérperas e profissionais de saúde. Ciênc Saúde colet 2011;16(12):4855-64.

23. Gonçalves AC, Bonilha ALL. Crenças e práticas da nutriz e seus familiares relacionadas ao aleitamento materno. Rev Gaúcha Enferm. 2005 dez;26(3):333-44.

24. Barbosa MARS, Teixeira NZF, Pereira WR. Consulta de enfermagem: um diálogo entre os saberes técnicos e populares em saúde. Acta paul enferm. 2007;20(2):226-9.

25. Marshall JL, Godfrey M, Renfrew MJ. Being a 'good mother': managing breastfeeding and merging identities. Soc Sci Med. 2007;65(10):2147- 59.

26. Primo CC, Caetano LC. A decisão de amamentar da nutriz: percepção de sua mãe. J Pediatr. 1999;75(6):449-55.

27. Gusman CR. Os significados da amamentação na perspectiva das mães [dissertação]. Ribeirão Preto (SP): Universidade Federal de São Paulo; 2005. 
28. Shimoda GT, Silva IA. Necessidades de saúde de mulheres em processo de amamentação. Rev Bras Enferm. 2010;63(1):58-65.

29. Oliveira DR, Gomes PR, Bando AMN, Gonçalves, SR. Crenças alimentares no aleitamento materno. Arq Bras Ciênc Saúde. 2011;36(2):67-71.

Recebido: $21 / 6 / 2013$

Aprovado: 10/9/2013 